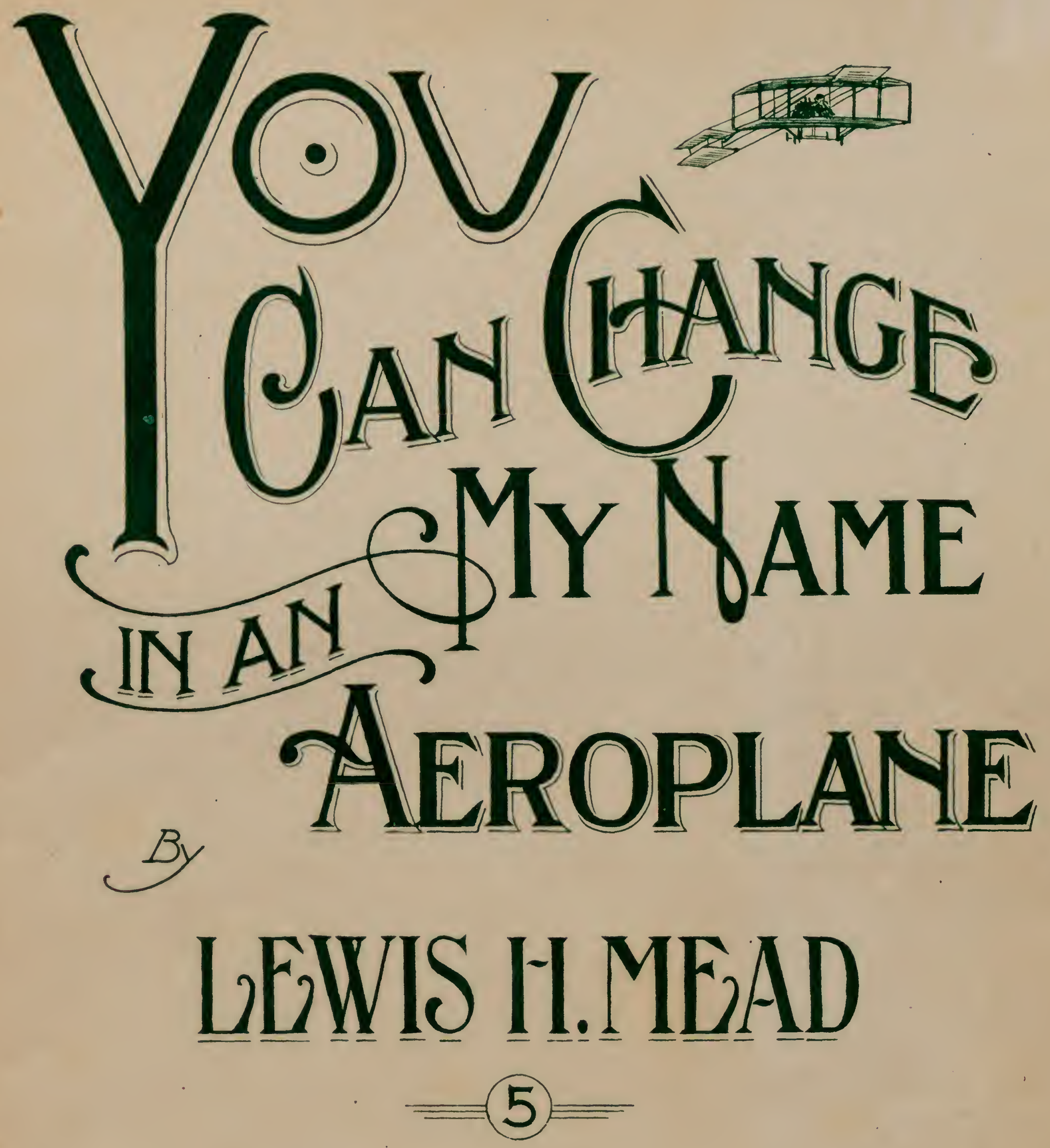

\author{
Published by \\ Tbe H. Kirkus Dugdale C. \\ Fourteenth $E$ You Sts. \\ WASHINGTON, D.C.
}





\section{You Can Change My Name, In An Aeroplane}

INTRO.

Valse Moderato
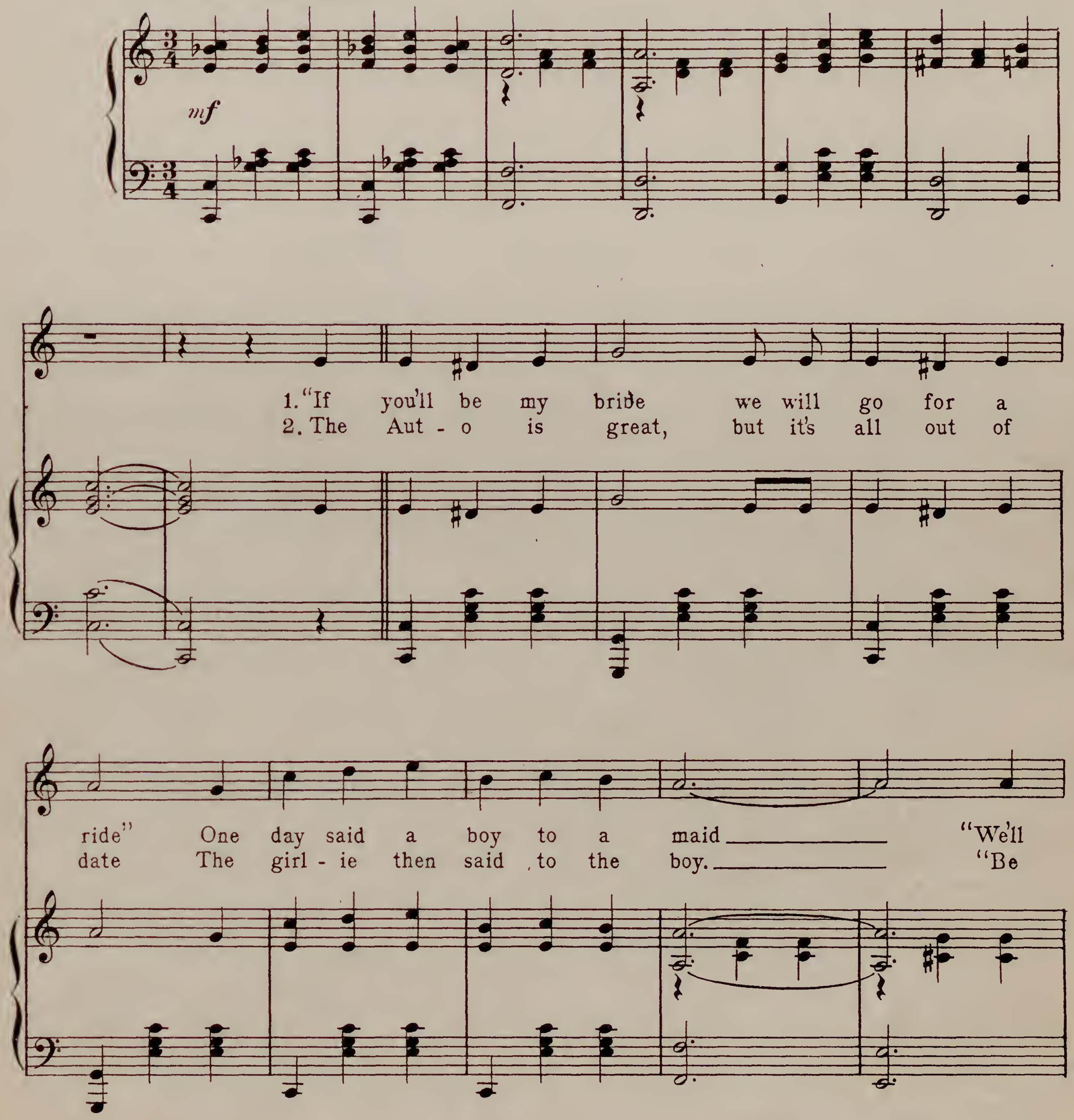

Copyrighted 1911 by Lewis $\mathrm{H}$. Mead

3061 Harrington Ave. Los Angeles, Cal. 


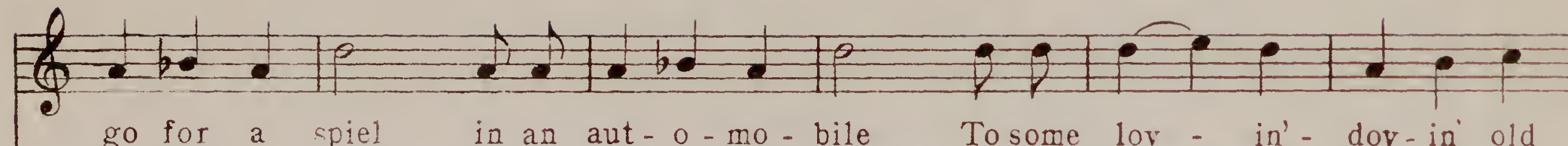
go for a spiel in an aut-o-mo-bile Tosome lor - in' - dov-in old
like Mis-ter Wright and I'l hug you up tight On a glid-ing, sky - rid-ing old
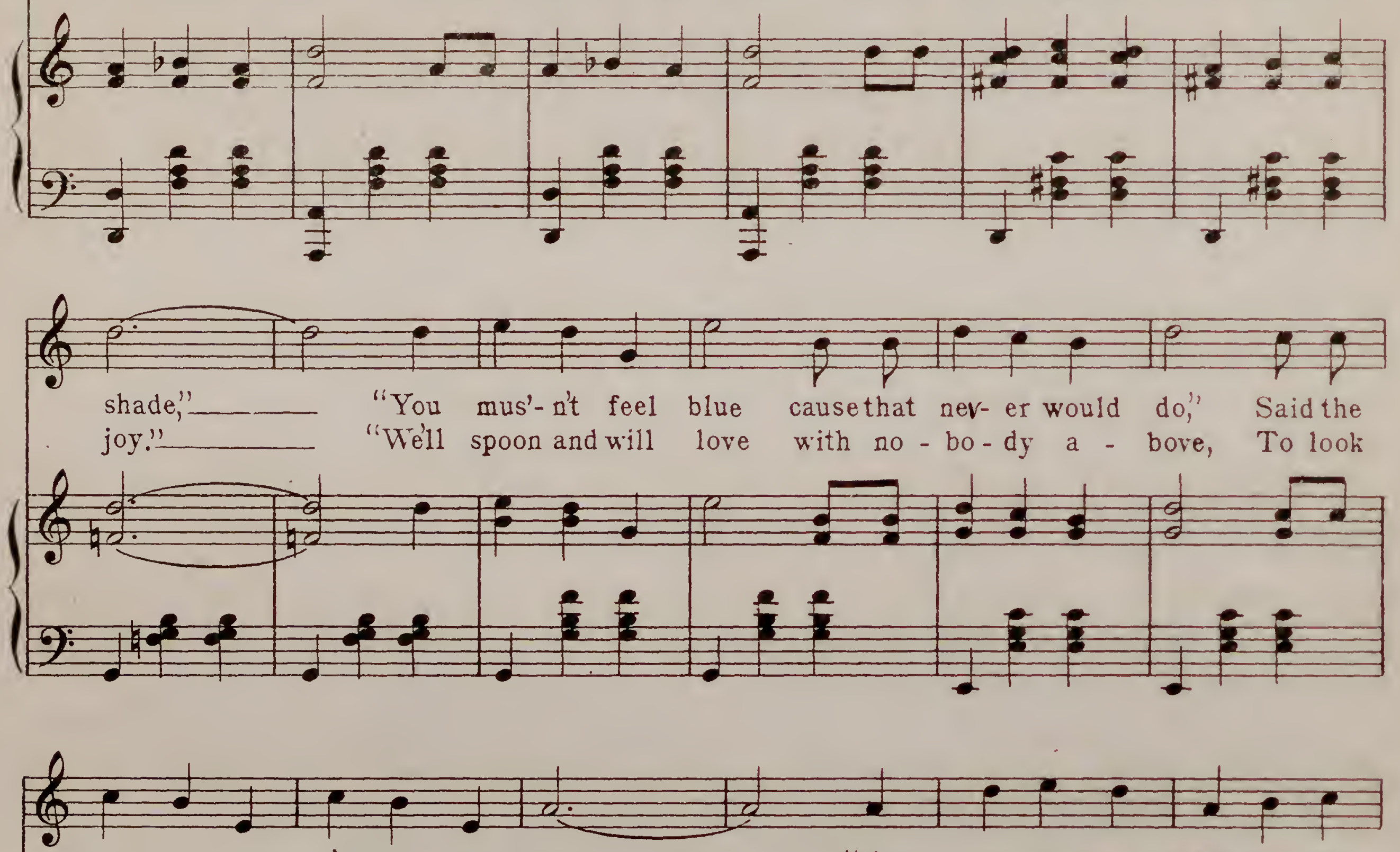
girl-ie and I'll tell you why._I've al-ways been wish-ing, its down on us two from on high._We'll nev-er stop slid-ing, for
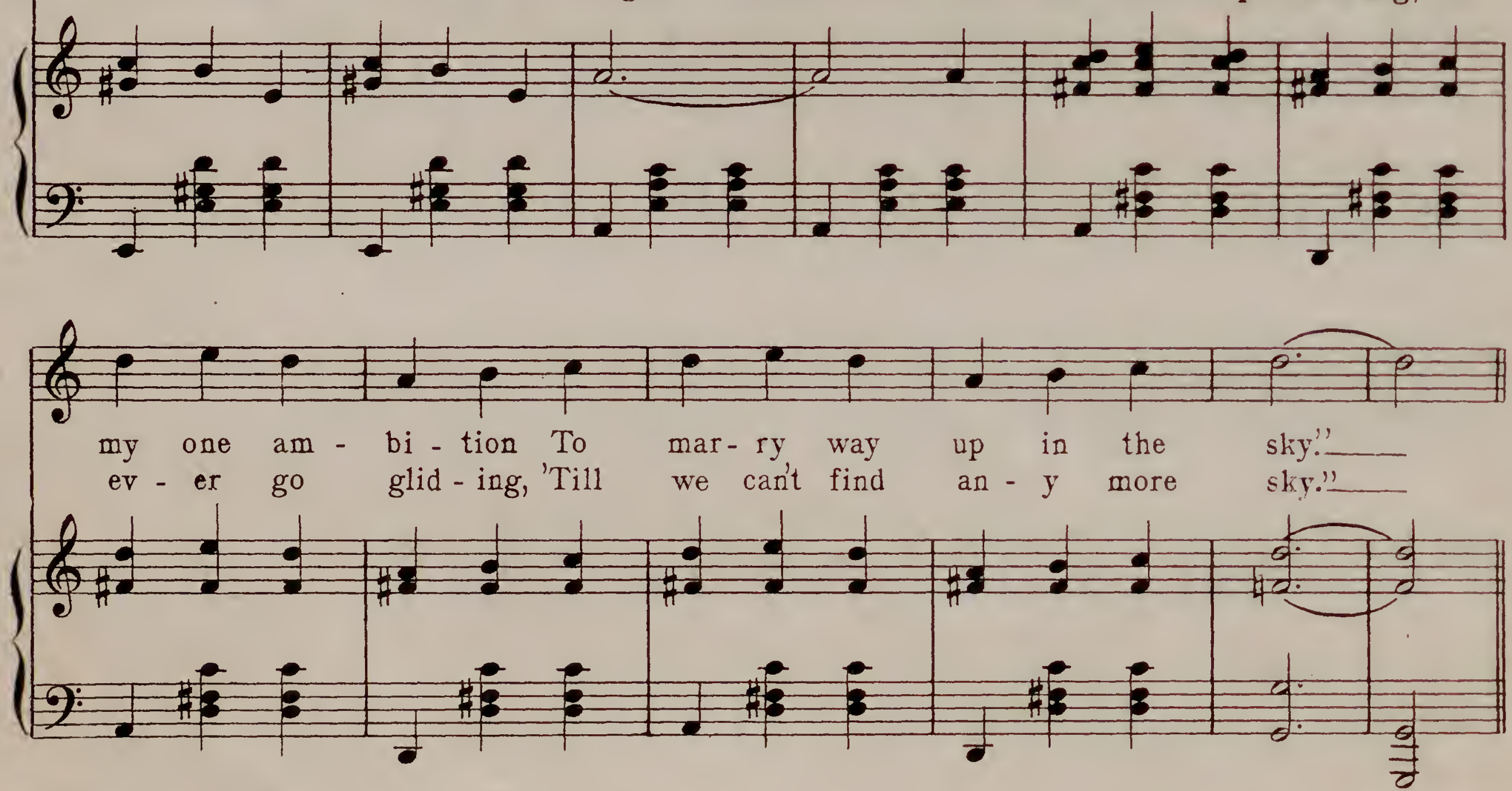

You Cau Chauge etc. Зs 
CHORUS

(a)

You can change my name in an aer-o-plane,Idontcare wheth-er in snow or in rain,___ I

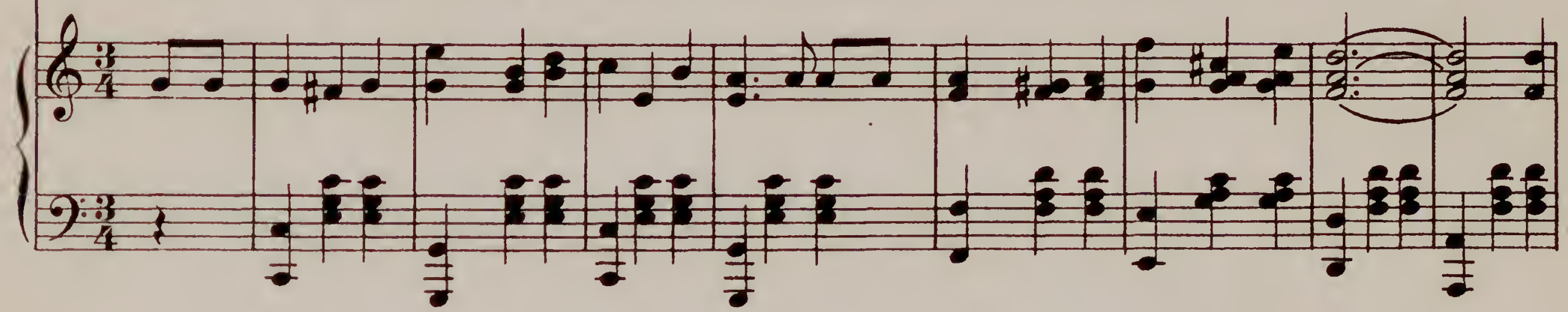

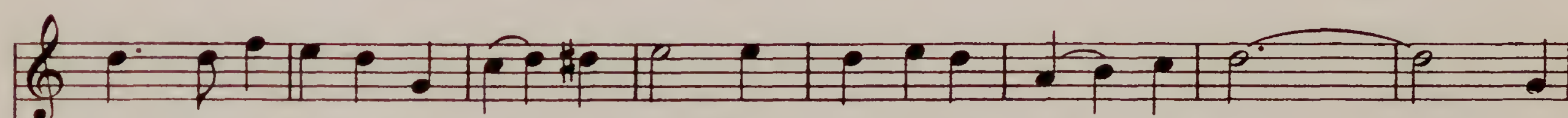

want to be fly-ing all 'night and day 'Way up in the milk - y way._I'd

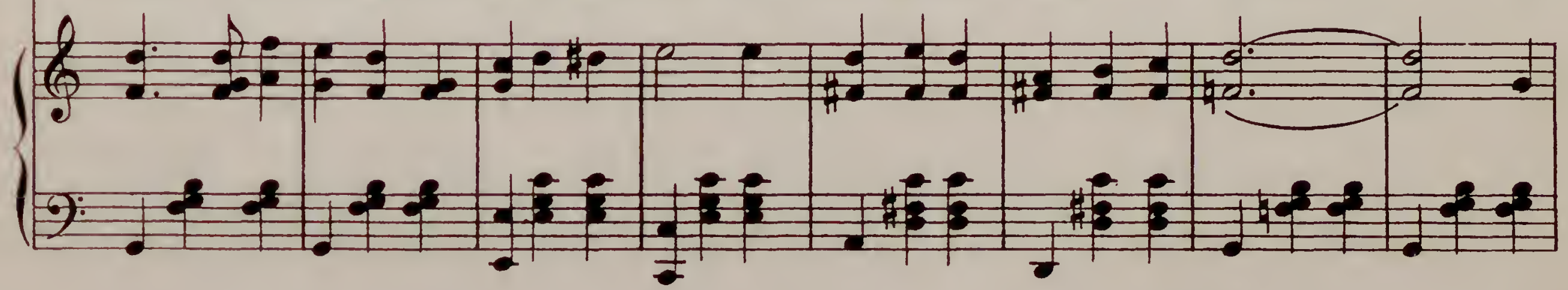

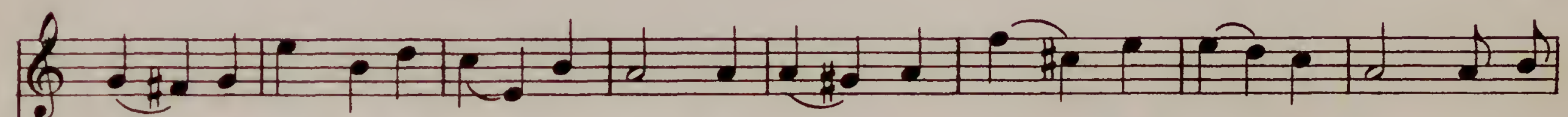
sure go loon in an old bal-loon A - sail - ing, sail - ing, 'round the moon But I'd

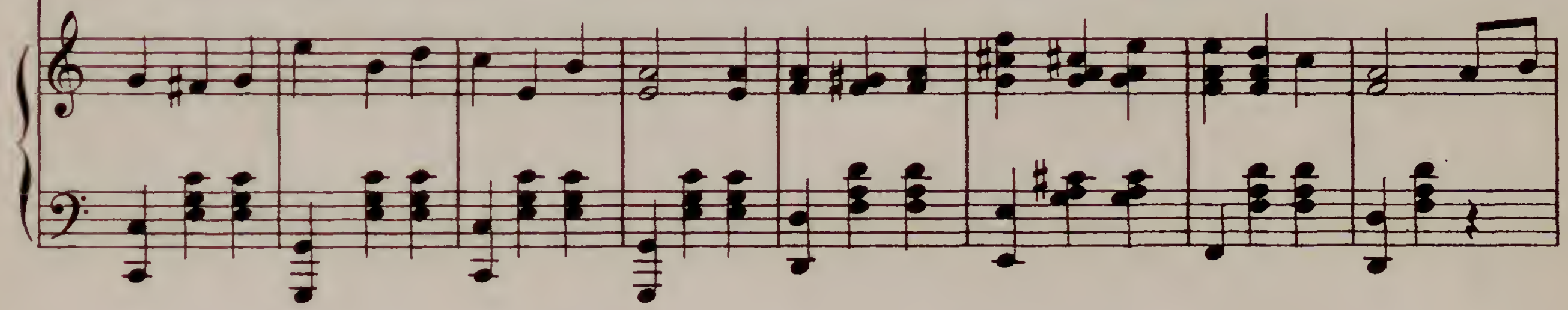

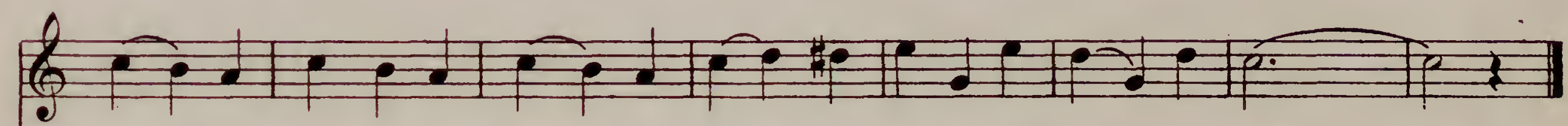
go - in sane if you changed my name In an-y old aer - o - plane.

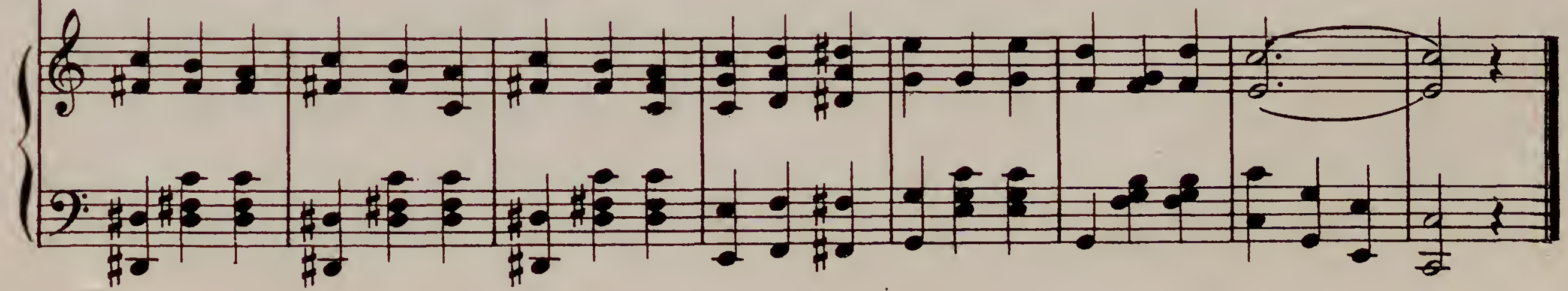

You Can Change etc. उ 


\section{Try this on your Piano.}

"ELEANORE"

Words by

ALFRED SCHROEDER.
Music by

M. MERECKI.
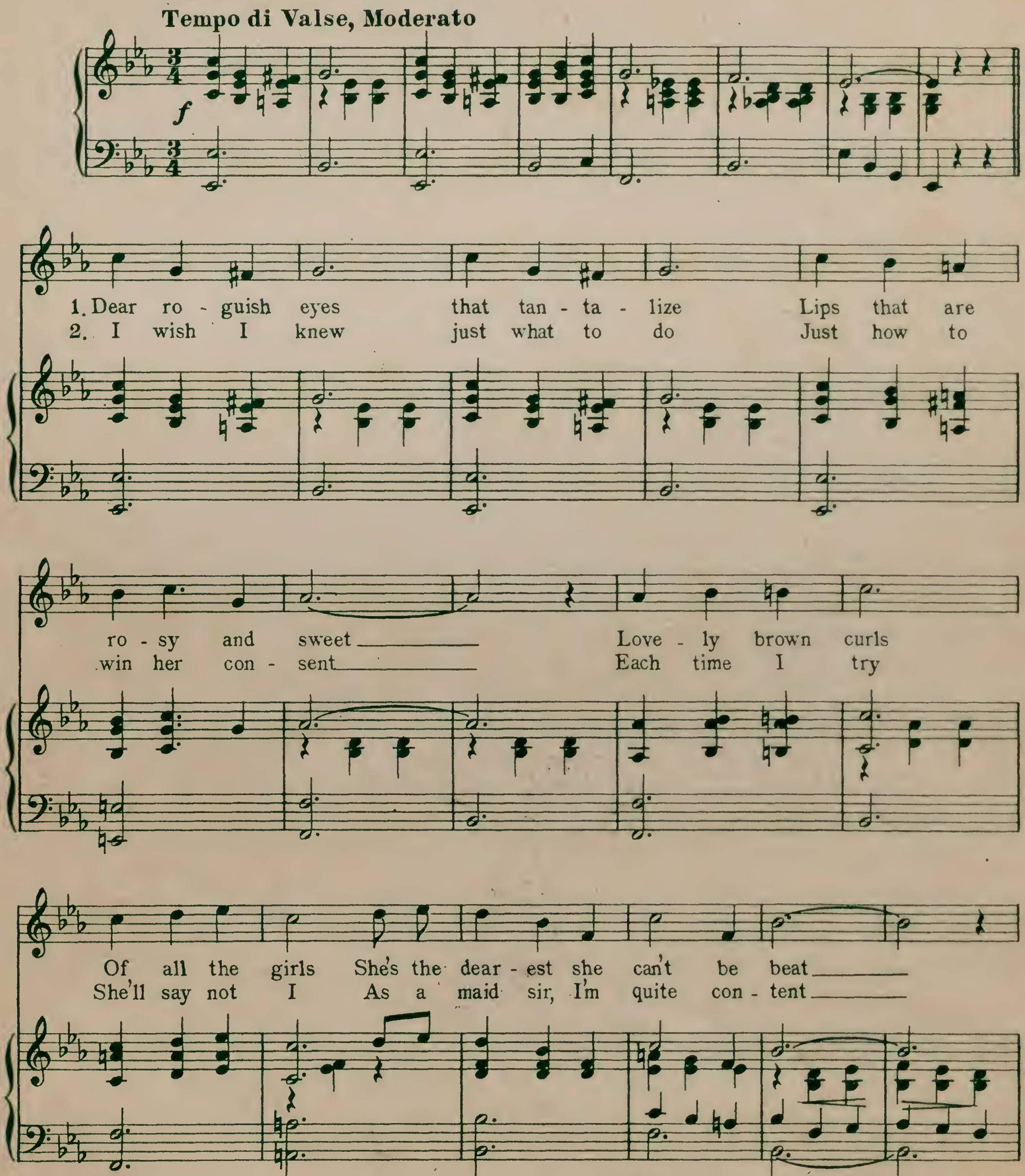

Copyrighted 1911 by M. Merecki.

215 Superior St., Detroit, Mich.

Send 15 for a complete of this popular number The h. KIRKuS DUGDale Co.,Publishers, WASHINGTON, D.C. 